\title{
Advanced Prostate Carcinoma
}

National Cancer Institute

\section{Source}

National Cancer Institute. Advanced Prostate Carcinoma. NCI Thesaurus. Code C156284.

A prostatic carcinoma that has spread extensively to other anatomical sites or is no

longer responding to treatment. 